\title{
Conflitos e Possibilidades em Áreas de Preservação Permanente Urbanas na Amazônia - Estudo na Lagoa dos Índios
}

\author{
MEDEIROS, José Marcelo Martins ${ }^{1}$ \\ ROMERO, Marta Adriana Bustos ${ }^{2}$ \\ MEDEIROS, Mariana Martins ${ }^{3}$ \\ ARAÚJO, Dayanne dos Santos ${ }^{4}$
}

\begin{abstract}
1Professor efetivo da Universidade Federal do Tocantins, Palmas, Brasil. medeirosjose@gmail.com 2Professora titular da Universidade de Brasília, Brasília, Brasil. bustosromero@gmail.com 3Professora efetiva Universidade Estadual do Amapá, Macapá, Brasil. eng.marimedeiros@gmail.com

${ }^{4}$ Graduada na Universidade estadual do Amapá, Macapá, Brasil. dayanneueap@gmail.com
\end{abstract}

\begin{abstract}
Resumo
Este artigo discute a relação entre ocupações em margens de rios em meio urbano na Amazônia e a arcabouço legal sobre Áreas de Preservação Permanente no Brasil. Apesar da pouca notoriedade dada às APPs em meio urbano, essas podem ser classificadas como um dos mecanismos de combate ao cenário de degradação nas cidades brasileiras. Portanto, se o Código Florestal fosse adequadamente respeitado pelas cidades brasileiras, grande parte das necessidades urbanas seria atendida. $O$ estudo de caso foi realizado nas áreas úmidas de Macapá, cidade tipicamente amazônicas, que sofre intensa ocupação urbana e deterioração da qualidade ambiental. A mudança de uso do solo nas margens da Lagoa dos Índios foi destacada, provando que as novas atividades vêm ocasionando seu assoreamento e alterando a morfologia de drenagens. Existe o descarte de efluentes líquidos e detritos domésticos produzidos tanto por habitações como órgãos públicos e comércio. Essa prática está relacionada à falta de monitoramento e fiscalização pelos órgãos ambientais, mas, sobretudo, pela ausência de infraestrutura urbana do município que não oferece serviços de saneamento básico.
\end{abstract}

Palavras-Chave: Amazônia, Áreas de Preservação Permanente, Macapá, Lagoa dos Índios.

\begin{abstract}
This paper discusses the relationship between the urban occupations in riverbanks in the Amazon and the Brazilian legal framework on Areas of Permanent Preservation (APPs). In spite of the low notoriety given to APPs in urban areas, they can be classified as one of the mechanisms to combat the degradation scenario in Brazilian cities. Therefore, if the Forest Code was adequately fulfilled in Brazilian cities, much of the urban needs would be met. The case study was carried out in the humid areas of Macapa, a typically Amazonian city that suffers intense urban occupation and deterioration of environmental quality. The alteration of soil use on the banks of the Lagoa dos Indios was highlighted, proving that the new activities are silting the lake and altering the drainage morphology. There is a disposal of liquid effluents and domestic debris produced by both public housing, public agencies and commerce. This practice is related to the lack of monitoring and inspection of environmental agencies, but mainly due to the lack of urban infrastructure in the municipality, that does not offer basic sanitation services.
\end{abstract}

Key-Words: Amazon, Areas of Permanent Preservation, Macapa, Lagoa dos Indios. 


\section{Introdução}

As importantes funções ambientais desempenhadas pelas margens dos rios e lagos justificam o seu enquadramento em uma categoria que precisa ser preservada, conhecida como "Área de Preservação Permanente" pelo Código Florestal Brasileiro (Lei 12.651/2012). Esses ecossistemas de água doce além de possuírem alta riqueza em biodiversidade, proporcionam serviços, sustento e moradia a milhões de pessoas em extrema pobreza (TURNER et al., 2007). Mensurar os valores da diversidade desses ambientes não é tarefa simples, visto que envolvem questões e valores culturais, éticos, religiosos, sociais e estéticos.

O conceito de APP, conforme Mello (2018) carregava inicialmente o princípio da intangibilidade, ou seja, a proibição de uso e ocupação humana. O princípio da intangibilidade chocava-se com usos urbanos tradicionais, inclusive com a "atração" que as margens de rios e lagos sempre exerceram sobre as pessoas. Dessa forma, a desconsideração das especificidades do meio urbano seria uma das razões para os conflitos das APPs nas cidades, o que gerava, segundo esta autora, um paradoxo:

[...] "de um lado, as múltiplas funções urbanísticas e o efeito de atração que os corpos d'água exercem sobre as pessoas; de outro, o dispositivo legal que impede a ocupação formal das margens dos corpos d'água no Brasil, visando à preservação das suas funções ambientais" (MELLO, 2008, p.26).

Portanto, no ambiente urbano, manter rigidamente o ambiente natural e estático não parece ser apropriado. O espaço urbano é singularmente antrópico, apropriado de forma desigual por diferentes grupos sociais e por atividades ligadas a produção, consumo, comércio, prestação de serviços, circulação, lazer e habitação, fatores fundamentais na ocupação do território e na determinação de suas características ambientais (SCAGLIUSI e SANTOS, 2011).

Historicamente é possível observar a influência das águas na distribuição da população no território Amazônico. As populações tradicionais (ribeirinhos) há séculos residem nas margens de canais e igarapés e por serem extrativistas, utilizam esses recursos como fonte de água, alimento, transporte e para escoamento de produtos.

Na Amazônia, a migração da população rural e ribeirinha em direção aos maiores núcleos urbanos em busca de melhor qualidade de vida acarretam invasões de várzeas (áreas úmidas ou alagadas), ou seja, das áreas de APPs. Os moradores com menores recursos constroem moradias sobre palafitas (estruturas de madeiras suspensas sobre o curso d'água) e aqueles com melhores condições aterram a área com materiais provenientes de resíduos de descarte da construção civil.

A aplicabilidade da disposição das APPs para as áreas urbanas na Amazônia levou à ilegalidade um enorme contingente de ribeirinhos, em sua maioria, pessoas pobres, com um estilo de vida próprio. Vários autores, como Borges e Rezende (2011), Ventura Neto e Cardoso (2012), Luz, Avanci e Cruz (2013), Araujo (2012), Rodrigues, Ferreira e Santos (2014) e Laurindo e Gaio (2014), identificaram posicionamentos sobre o uso e ocupação irregular das margens de rios urbanos.

Este artigo discute a relação entre ocupações em margens de rios em meio urbano na Amazônia e o arcabouço legal sobre Áreas de Preservação Permanente no Brasil. Especificamente, voltamo-nos para as formas de interação social desenvolvidas entre comunidades urbanas situadas nas periferias de capitais da região Norte.

\section{O Novo Código Florestal e as Áreas de Preservação Permanente:}

Em seus primórdios, a legislação ambiental brasileira focava apenas o tratamento da matéria a partir das perspectivas do direito econômico. Como ilustra Silva (2015), a primeira lei penal que incidiu sobre infrações praticadas contra o meio ambiente foi o Código Criminal de 1830, que em seus artigos 178 e 257, penalizava o corte ilegal de madeira. A legislação protetiva da fauna e flora durante todo o século XIX e grande parte do século XX tinham os objetivos de regulação de atividades econômicas, sem grandes preocupações ecológicas. Como exemplos, têm-se o Código de Caça (Lei no 5.197/65) e o Código de Pesca (Decreto-Lei n.ำ 221/67).

No entanto, como ressalta Santana (2013), com o início das preocupações ambientais geradas principalmente a partir da Conferência de Estocolmo (1972) e outras conferências internacionais que o Brasil também era signatário, as questões ambientais e a ideia de que os recursos naturais não eram infinitos começaram lentamente a serem refletidas nas leis nacionais. A partir da Constituição de 1988, é possível notar uma mudança de paradigma a favor da tutela do meio ambiente pelo Estado. Segundo 
Antunes (1992), a Carta Magna de 1988 trata a problemática ambiental de forma detalhada, de maneira que o meio ambiente equilibrado é uma condição para a melhor qualidade de vida no país. Segundo esse autor:

[...] "desde a Conferência de Estocolmo, o meio ambiente e a ecologia vêm tornando-se um assunto mais e mais frequente na imprensa, nos Parlamentos e mesmo nas conversas familiares de todo o planeta. A Constituição de 1988 foi promulgada 16 anos após a primeira conferência das Nações Unidas sobre meio ambiente e, portanto, em meio a todo um debate de reformulação das relações do homem com a natureza" (ANTUNES, 1992, p. 312).

No capítulo 225, sob o título "Da ordem social", a Constituição dedica um capítulo específico ao meio ambiente, prevendo a todos um meio ambiente equilibrado, "impondo-se ao Poder Público e à coletividade o dever de defendê-lo e preservá-lo para as presentes e futuras gerações" (SILVA, 2015, p.18). Desse modo, a omissão do poder público em tomar medidas cabíveis relacionadas ao meio ambiente não são aceitas.

Como afirma Barros et al. (2015), com a inserção de novos parâmetros de preservação, a reserva de vegetação nativa deixou de ser apenas uma fonte de recurso madeireiro e passou a ter função ambiental. A Medida Provisória n.․ 2.166-67/2001 transformou o conceito de Florestas de Preservação Permanente para Área de Preservação Permanente (APP), de forma a instituir a área a ser preservada, estando ela coberta ou não por vegetação.

O debate sobre a necessidade de conservação de áreas de vegetação nativa é constante em nosso país. A vocação agropecuária do território brasileiro pressiona áreas onde esse processo produtivo ainda não foi inserido. A reforma do Código Florestal brasileiro no ano de 2012 provocou intensos debates nesse sentido e entre os pontos polêmicos estava a delimitação das Áreas de Preservação Permanente, as APPs. O conceito vigente de APP é definido nos seguintes termos:

II - Área de Preservação Permanente - APP: área protegida, coberta ou não por vegetação nativa, com a função ambiental de preservar os recursos hídricos, a paisagem, a estabilidade geológica e a biodiversidade, facilitar o fluxo gênico de fauna e flora, proteger o solo e assegurar o bem-estar das populações humanas (Lei oㅜ 12.651/12, artigo 3ํㅡㄹ inciso II).

O Código Florestal Brasileiro foi criado em 1934 e reeditado em 1965 (Lei n.o 4.771) e 2012 (Lei n.ำ 12.651), definindo os princípios necessários para proteger o meio ambiente e garantir o bem-estar da população. Segundo Garcia (2012), o Código Florestal trata das duas principais fontes de proteção ambiental - previstas através de situações de preservação e conservação - que são as Areas de Preservação Permanente (APP) e a Reserva Legal (RL).

Como afirma Garcia (2012), estudos apontam que não era necessário revisar o Código Florestal para permitir a continuidade do desenvolvimento do setor agropecuário no país. Conforme Silva et al. (2009), a organização ambientalista World WildLife Fondation, WWF-Brasil, por exemplo, em estudo realizado em 2009, defende a teoria de que seria possível ao Brasil mais que dobrar a sua área agricultável somente promovendo a recuperação de áreas de pastagens degradadas para o uso agrícola. $O$ atual Código florestal só terá eficiência se houver um controle e gestão efetivos do poder público, algo posto como difícil desde a época do Código de 1965, considerando os conflitantes interesses envolvidos.

Uma das principais críticas dos ruralistas ao Código Florestal é a sua falta de embasamento científico para a definição das metragens das faixas de APPs. Porém, os ambientalistas afirmam que se forem realizados estudos nesse sentido, a metragem mínima a ser protegida para se garantir a preservação da biodiversidade iria ser muito superior as atuais vigentes na lei. Metzger (2010), por exemplo, alerta para o fato de que apesar de não haver base científica para definir as larguras das APPs, em muitos casos estas deveriam ser muito maiores do que as estipuladas na lei. $O$ pesquisador se questiona se essa largura não deveria variar com a topografia da margem, com o tipo de solo, com o tipo de vegetação, ou com o clima e em particular com a pluviosidade local.

É importante ressaltar que o conhecimento dos processos ecológicos atuantes nas zonas ripárias ainda é muito limitado. Conforme Lima (1996), os estudos das larguras de faixas de proteção ao longo de margens de cursos d'água não são conclusivos. Para esse autor:

"Os limites da zona ripária, do ponto de vista geomorfológico, não são facilmente delimitados; podem variar bastante ao longo da microbacia e, principalmente, entre 
diferentes microbacias, em função das diferenças de clima, geologia e solos [...] Não existe ainda nenhum método definitivo para o estabelecimento da largura mínima da faixa ripária que possibilite uma proteção satisfatória do curso d'água" (LIMA, 1996, p.312).

Felizmente o Código Florestal (2012) manteve as regras e limites para as APP's e Reserva Legal, de modo geral. Umas das novidades corresponde ao CAR (Cadastro Ambiental Rural), registro nacional obrigatório das propriedades rurais, que permitirá ao poder público controlar a utilização e a ocupação do solo. Outra inovação foi a tentativa de se dar um enfoque mais científico às questões referentes à preservação do meio ambiente, propondo a realização de estudos técnicos regionalizados através de Zoneamento Econômico Ecológico. Porém, como esses estudos são realizados pelos estados, muitos ambientalistas temem que os governos estaduais criem suas próprias regras de acordo com interesses locais e dos grandes produtores. Conforme o Art. 40 do Código Florestal, considera-se Área de Preservação Permanente, em zonas rurais ou urbanas:

I - as faixas marginais de qualquer curso d'água natural perene e intermitente, excluídos os efêmeros, desde a borda da calha do leito regular, em largura mínima de:

a) 30 (trinta) metros, para os cursos d'água de menos de 10 (dez) metros de largura;

b) 50 (cinquenta) metros, para os cursos d'água que tenham de 10 (dez) a 50 (cinquenta) metros de largura;

c) 100 (cem) metros, para os cursos d'água que tenham de 50 (cinquenta) a 200 (duzentos) metros de largura;

d) 200 (duzentos) metros, para os cursos d'água que tenham de 200 (duzentos) a 600 (seiscentos) metros de largura;

e) 500 (quinhentos) metros, para os cursos d'água que tenham largura superior a 600 (seiscentos) metros;

II - as áreas no entorno dos lagos e lagoas naturais, em faixa com largura mínima de:

a) 100 (cem) metros, em zonas rurais, exceto para o corpo d'água com até 20 (vinte) hectares de superfície, cuja faixa marginal será de 50 (cinquenta) metros;

b) 30 (trinta) metros, em zonas urbanas; (Lei $n .{ }^{\circ} 12.651 / 12$, artigo $4^{\circ}$ ).

\section{3. Áreas de Preservação Permanente Em Meio Urbano:}

Apesar da pouca notoriedade dada às APPs em meio urbano, e da necessidade de estudos mais específicos sobre o assunto, essas podem ser classificadas como um dos mecanismos de combate ao cenário de degradação nas cidades brasileiras. A conservação da vegetação nativa nessas áreas, além de contribuir para o equilíbrio ecossistêmico, também tem relevância para a regulação das cheias, sendo uma contribuição de grande valor para as cidades, estando vinculada à redução de alagamentos e manutenção do abastecimento hídrico.

No entanto, os limites das APPs são constantemente infringidos, seja por ocupações irregulares ou canalização das suas margens. A criação da legislação referente às APPs poderia ter concebido milhões de metros quadrados de áreas verdes nas cidades brasileiras, mas, como alerta Macedo (2012):

"Em alguns grandes aglomerados urbanos, tais medidas se mostram tardias e inócuas, devido à ocupação destas áreas por elementos de sistema viário e favelas, tornando sua viabilidade quase impossível. Este é o caso dos corpos d'água dos municípios centrais da metrópole paulistana, que estão praticamente todos tamponados ou canalizados e têm sua vegetação ribeirinha irremediavelmente perdida" (MACEDO, 2012, p.98).

A primeira normatização para a permissão do uso das APPs em meio urbano foi disposta no art. 4ํำ do Código Florestal de 1965, através das modificações editadas pela Medida Provisória (MP) 2.166-67 de 2001. Nessa norma, a supressão de vegetação em APP era permitida desde que devidamente caracterizada a utilidade pública ou o interesse social da área. Conforme Borges et al. (2011), essa regulamentação recebeu várias críticas, pois considerou apenas a "supressão de vegetação" em APP. A lei não trouxe e nem definiu os critérios que permitiriam promover a alteração de uma APP quando "desprovida de vegetação", o que ocorre com grande frequência nas cidades, principalmente nas áreas mais centrais. 
Segundo Borges et al. (2011), visando sanar essa polêmica, a resolução do CONAMA n. .969 de 2006 acrescentou ao termo "supressão de vegetação" o termo "intervenção". Assim, o termo intervenção em APP pode ser considerado tanto para atividades em APPs desprovidas de vegetação, bem como aquelas com ocorrência de vegetação. Foi essa resolução que regulamentou casos excepcionais de utilidade pública ou interesse social para a supressão de vegetação em APPs, abrindo caminho para a implantação de projetos de parques lineares e para a urbanização de assentamentos ilegais nessas áreas.

"As atividades de utilidade pública podem ser entendidas como aquelas que têm aplicação pública em sentido mais amplo, sem distinção de grupos sociais específicos e que atendam interesses gerais; já as atividades de interesse social são aquelas que caracterizam os interesses de grupos sociais menores, inclusive familiares" (BORGES et al, 2011, p. 1206).

As leis atuais que objetivam a proteção das APPs não as diferenciam se estão nas áreas urbanas ou rurais. No contexto urbano, onde existe alto grau de impermeabilização do solo, a aplicação da legislação é muito difícil tendo em vista que as faixas de proteção podem chegar até o meio quilômetro dependendo da dimensão dos cursos hídricos, podendo chegar até a englobar bairros inteiros. A realidade é que as APPs têm sido simplesmente ignoradas na maioria das cidades.

Um dos pontos nodais desses problemas é que "ainda há dificuldades em estabelecer critérios apropriados para a recuperação das APPs em áreas urbanas" (BORGES et al, 2011, p. 1209). Muitas vezes existe falta de estudos apropriados para a bacia hidrográfica, outras vezes os próprios problemas advindos do adensamento populacional dificultam a recuperação das áreas degradadas.

Carvalho e Francisco (2003) discorrem sobre as medidas mitigadoras a serem adotadas em APPs para que possam significar um atrativo paisagístico de importância maior. Para os autores, dada a natureza da preservação, coloca-se que o desenho de parques lineares, assim como usos urbanos menos densos ao longo das margens, perfazem uma estratégia adequada de compatibilizar as APPs em meio urbano.

[...] "o desenho de parques lineares, assim como usos urbanos menos densos (agricultura urbana, grandes equipamentos sociais, zonas de baixa taxa de ocupação, etc.), ao longo dos cursos d'água perfazem uma estratégia adequada de compatibilizar esta ambiência tão diferenciada na cidade. Seriam áreas de transição em densidades urbanas que ajudariam, estendendo a função das APP, a minimizar os impactos da urbanização" (CARVALHO e FRANCISCO, 2003, p.09).

Carvalho e Francisco (2003) concluem que é preciso procurar um modo diferente de se construir cidades, procurando uma nova estética, em que a urbe não seria a negação da natureza. O "mato" das APPs, nessa nova estética, seria natural, bonito e agradável, e a população poderia criar uma nova afetividade com as áreas livres das cidades.

Mais recentemente, Macedo, Queiroga e Degreas (2012) também tocaram no tema da falta de importância do caráter social na legislação sobre APPs. Segundo os autores, a legislação brasileira de APPs não faz referência à melhoria do sistema de espaços livres de uma cidade, preocupando-se quase que exclusivamente com a estabilidade do solo e a proteção por meio da vegetação dos corpos d'água, sem se preocupar com as demandas cotidianas dos habitantes de uma cidade.

"Não se pode negar que um bom sistema de drenagem, com águas e nascentes íntegras e a existência de vegetação de porte não sejam necessidades urbanas de uma cidade tropical, mas as prescrições legais não estão associadas diretamente a demandas estruturais humanas e urbanas, como circulação e atividades de recreação, do cotidiano de cada família e cidadão" (MACEDO, QUEIROGA e DEGREAS, 2012, p.6).

No entanto, a APP visa, sobretudo, a proteção dos recursos hídricos, preocupação humana desde sempre. Portanto, se o Código Florestal fosse adequadamente cumprido pelas cidades brasileiras, grande parte das necessidades urbanas seriam automaticamente atendidas.

\section{4. Áreas de Preservação Permanente na Amazônia:}


De acordo com o atual Código Florestal (Lei no 12.651/12, art. $4^{\circ}$, I) as áreas de Preservação Permanente devem ser demarcadas a partir do leito regular do corpo d'água. Entretanto, esse conceito de regularidade de leito de rios não é aplicável para Amazônia, onde existem variações sazonais. A amplitude entre os níveis máximo (pico de cheia) e mínimo (vazante) pode variar em até 20 metros.

Na versão anterior do Código Florestal a demarcação era feita a partir do leito mais alto do rio. Essa modificação da Lei, conforme Laurindo e Gaio (2014), representa um grave prejuízo ambiental, pois implica em redução das dimensões das APPs, desrespeitando o princípio da proibição de retrocesso ambiental adotado pela Constituição de 1988. A diminuição das APPs também aumenta riscos aos habitantes citadinos e ribeirinhos, que sofrem com as inundações e os "desbarrancamentos/erosões" nas margens dos rios. Conforme estes autores:

"A diminuição do referido espaço ambiental protegido não se baseou em estudos técnicos e científicos, o que demonstra a ausência de justificação constitucional para a referida medida, por consequência, não se pode aqui invocar a aplicação dos princípios constitucionais da razoabilidade e proporcionalidade" (LAURINDO e GAIO, 2008, p.08).

Na Amazônia as várzeas e áreas úmidas desempenham um papel ecológico fundamental no equilíbrio ecossistêmico local, além de proporcionar bens e serviços para o homem. Particularmente no estado do Amapá, é grande o número de áreas de várzea situadas nas zonas urbanas e periurbanas das cidades de Macapá e Santana. Estas áreas vêm sendo ocupadas progressivamente, devido à falta de planejamento urbano e de políticas públicas adequadas para o produtor rural, agravado pelos altos índices migratórios de pessoas oriundas de outros estados da Federação brasileira.

As áreas úmidas de Macapá e Santana, cidades tipicamente amazônicas, sofrem intensa ocupação urbana, apresentando expressiva deterioração da qualidade ambiental, devido, principalmente, ao lançamento direto nos corpos d'água de dejetos e efluentes domésticos não tratados (figura 1).

Figura 1: Pressão urbana sobre áreas alagadas em Macapá, AP - margens da Lagoa dos Índios.

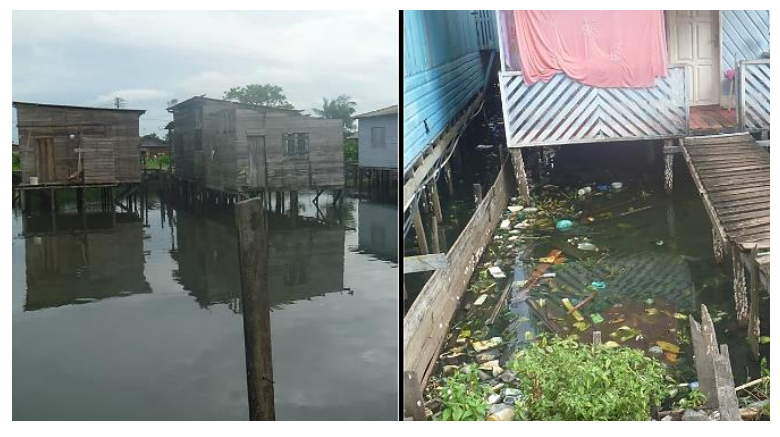

Fonte: arquivo dos autores

Os resultados de três anos de investigação na calha do Igarapé da Fortaleza, o principal curso d'água ligado às principais ressacas de Macapá e Santana, indicam um significativo grau de comprometimento e degradação ambiental onde a retirada das matas ciliares, erosão das margens, assoreamento intensivo e urbanização desordenada, trazem reflexos negativos para a qualidade da água da bacia hidrográfica (CUNHA et al., 2003).

Porém, apesar dos assentamentos informais em áreas de APP compreenderem a principal tensão entre as agendas ambiental e urbana, é preciso reconhecer que os pobres não são os únicos atores (MARICATO, 1996). A omissão do poder público e a ganância de proprietários fundiários e imobiliários também são responsáveis pelas ocupações em APPs. Como afirma Romero (2001) uma consequência da expansão urbana no Brasil tem sido a redução de áreas com vegetação nativa devido às intervenções que desconsideram completamente os elementos naturais da paisagem. A prática da construção concretiza-se sem considerar os impactos que provocam no meio ambiente, repercutindo não somente no desequilíbrio do meio, como também no conforto e na salubridade da população urbana.

\section{Estudo na Lagoa Dos Índios - Macapá:}


O setor costeiro estuarino ou amazônico do Amapá é banhado pelas águas do rio Amazonas e se caracteriza por possuir planícies fluviais inundáveis denominadas localmente como "ressacas". A ressaca da Lagoa dos Índios, compreende um ecossistema ricos e biodiverso, drenado por água doce, ligada ao curso principal d'água, o Igarapé da Fortaleza, e influenciada fortemente pela pluviosidade.

O processo de ocupação das áreas de ressacas na cidade de Macapá teve início por volta da década de 1950. No entanto, é a partir da segunda metade da década de 1980 que este processo de ocupação se intensificou, fazendo com que a alteração na estrutura dessas áreas acontecesse de forma cada vez mais acelerada (PORTILHO, 2010).

Desde 1999 as áreas de ressaca foram tombadas como patrimônio natural (Lei n. 0455/1999 revogada pela Lei n. 835/2004) e passaram a ser proibidas instalações de atividades poluidoras, usos do solo que intensificassem processos erosivos e atividades lesivas à biodiversidade. Além do mais, o Plano Diretor de Macapá-AP, Lei Municipal no 029/2004, elaborado de forma participativa, reconheceu as áreas de ressacas como patrimônio ambiental municipal e determinou várias ações de uso e conservação.

Ao longo do tempo as intervenções na Lagoa dos Índios, passaram de quase imperceptíveis a degradação, devido às atividades relacionadas com a expansão urbana desordenada, intensificadas nas décadas de 1980 e 1990 ocasionando diversos conflitos socioambientais (VARGAS e BASTOS, 2013). Em decorrência dos impactos antrópicos em ressacas de Macapá e Santana, no início da década de 2000 foram realizados os primeiros estudos específicos para a caracterização e diagnóstico dessas áreas (TAKIYAMA, 2004; TAKIYAMA, 2012). Os diagnósticos apontaram que as principais atividades que causam impactos ambientais nessas áreas são: ocupação desordenada do solo, queimadas intencionais, descarte inadequado de resíduos e pastagem para os búfalos. Outras atividades comuns nas áreas de ressaca são: a extração de argila para olarias, a caça e a pesca de subsistência, a piscicultura, a navegação, a extração vegetal e a recreação.

Em relação à Lagoa dos Índios (figura 2), Bastos (2006), destaca que as atividades executadas no entorno desta vêm ocasionando seu assoreamento e alterando a morfologia de drenagens. Essa autora verificara o descarte de efluentes líquidos e detritos domésticos produzidos pela presença de atividades de órgãos públicos e das habitações. Essa prática está relacionada à falta de monitoramento e fiscalização pelos órgãos ambientais, mas, sobretudo, pela ausência de infraestrutura urbana do município que não oferece serviços de saneamento básico (BASTOS, 2006).

Figura 2: Localização da área de estudo

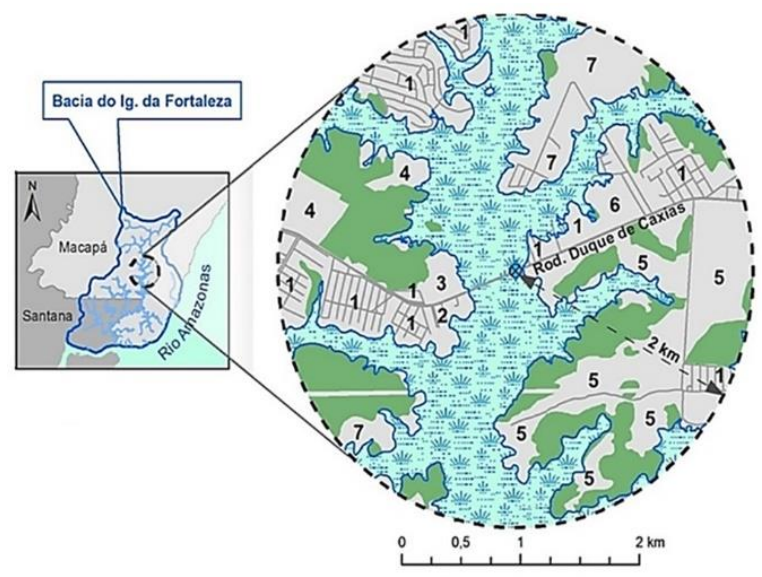

Legenda

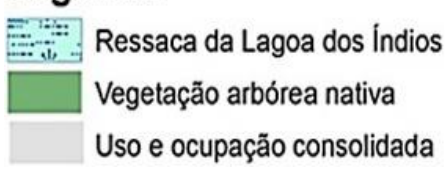

Fonte: composição dos autores.

\section{O Degradação das APPs e suas Implicações na Qualidade Ambiental da Lagoa}




\section{dos Índios em Macapá}

À noroeste do entorno da área de ressaca da Lagoa dos Índios, no período compreendido entre os anos de 2009 e 2014, observou-se significativas modificações na ocupação do solo. De acordo com o Plano Diretor de Ordenamento Territorial- PDOT (Lei o 029/2004) essa área era prevista como Setor Residencial.

Em 2009, essa área não possuía edificações, mas ao longo do tempo passou a ser ocupada em decorrência da expansão urbana, que ocorreu de forma horizontal e desordenada. As análises da imagem de satélite do ano de 2014, demonstram que a região passou por um processo de desmatamento da vegetação nativa dando lugar ao bairro conhecido popularmente como "Marabaixo IV", uma expansão do bairro Marabaixo (figura 3).

Figura 3: uso do do solo - Lagoa dos Índios

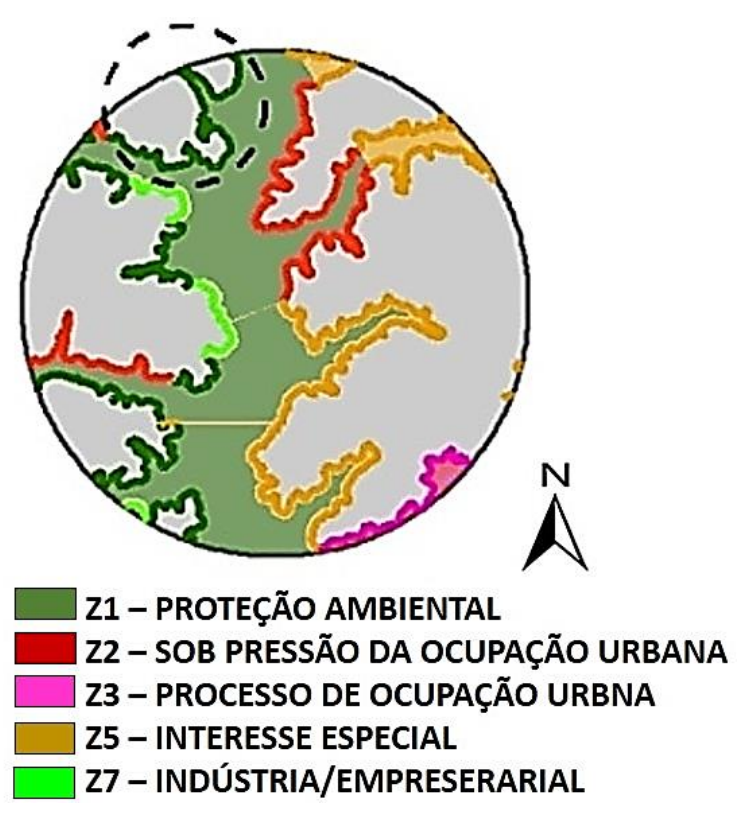

Fonte: Geodados IEPA. Layout: Jadson C. Almeida.

À noroeste da lagoa, a qualidade ambiental foi alterada significativamente, onde se consolidou o bairro Marabaixo IV. Portanto, este estudo propõe a atualização do zoneamento com a modificação para de "Zona Sob Pressão da Ocupação Urbana" (figuras 4 e 5). 


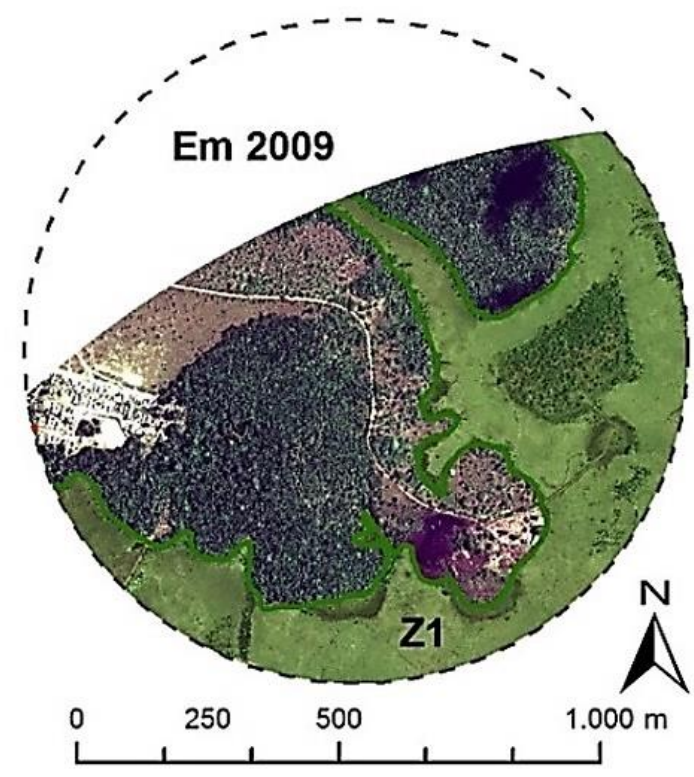

Fonte: WGS 84. UTM 22N. GeoDados: IEPA. Layout: Jodson C. Almeida. UEAP, 2015.

Figura 5 - ocupação do solo em 2014

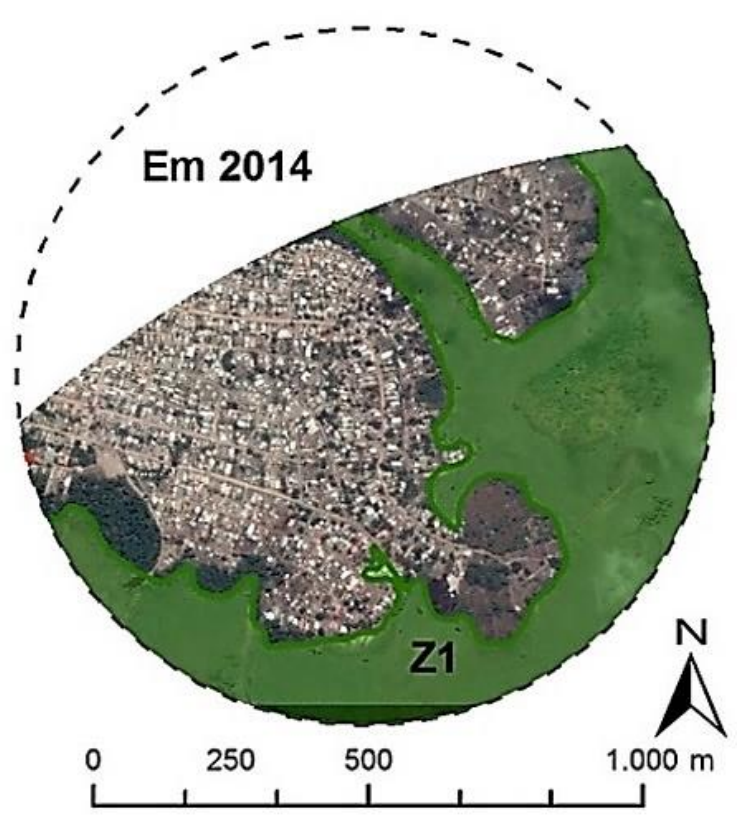

Fonte: WGS 84. UTM 22N. GeoDados: IEPA. Layout: Jodson C. Almeida. UEAP, 2015.

Em vistoria de campo (figuras 6 a 9), foi constatado que os moradores do bairro Marabaixo IV são em sua maioria de baixa renda, isso ficou perceptível quando observou-se as casas de alvenaria e madeira, pequenas e mal planejadas, resultantes do processo de ocupação/invasão. A infraestrutura é precária, contando apenas com uma iluminação pública nos principais acessos. Logo, não existe pavimentação, rede de água encanada, rede de esgoto ou sistema de endereçamento. A falta de saneamento é comum no município de Macapá, o bairro central, por exemplo, é o único que conta com rede encanada de água e coleta de esgoto.

Em relação ao abastecimento de água observou-se que a população perfura poços, porém estes não são realizados segundo projetos ou licenciamento. Há ainda alguns residenciais e casas de moradores de média-alta renda que invadem a área de ressaca com infraestruturas para lazer e atividades agrícolas. Notou-se ainda alguns terrenos receptores de atividades poluidoras devido aos descartes 
inadequados de materiais. A prática de queimadas, como forma de limpeza do terreno, é outro fator que ficou visível nas vistorias e que causa sérios problemas para qualidade ambiental.

Figura 6 a 9 - Fotos de inspeções de campo da área de estudo.
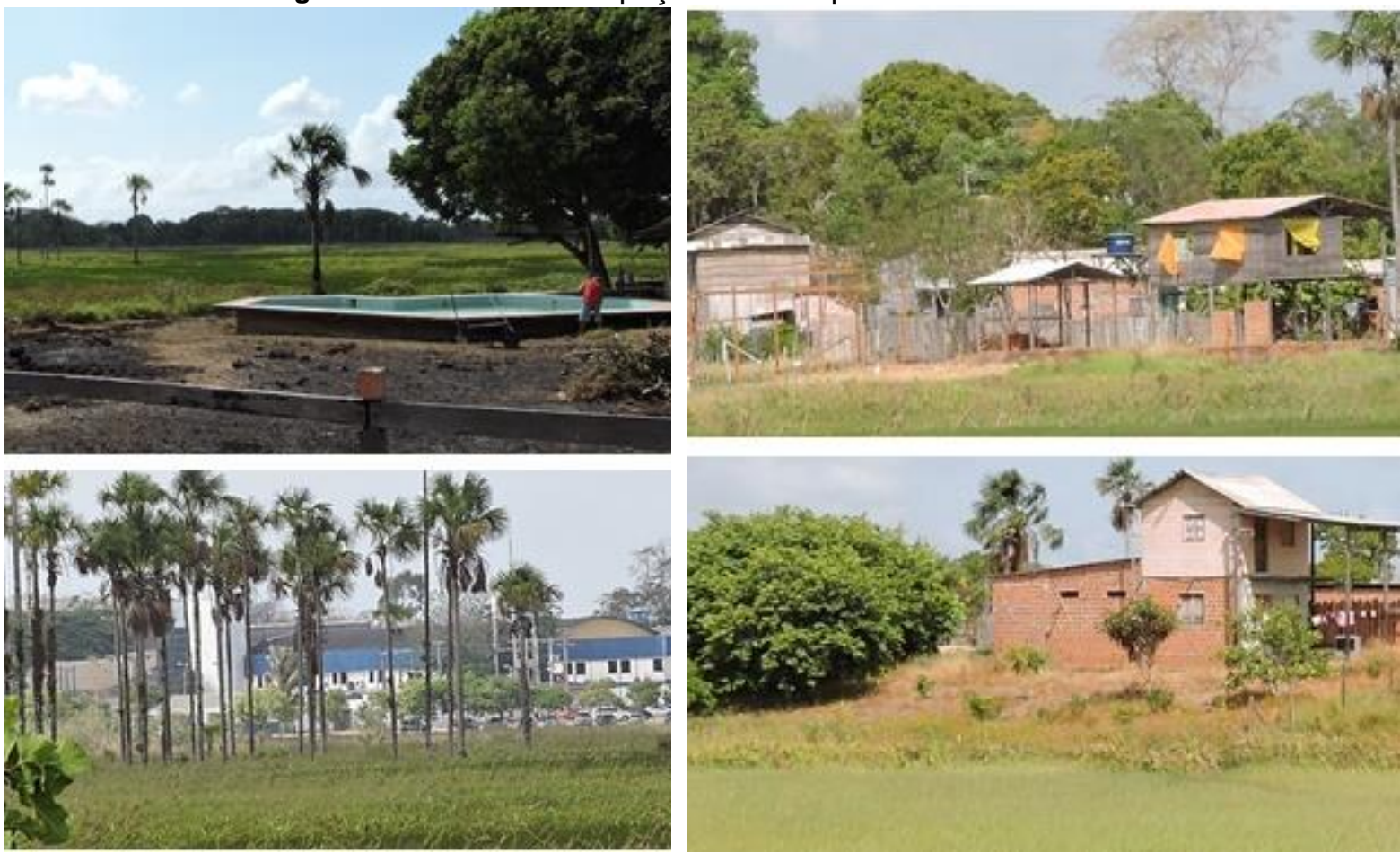

Fonte: fotos dos autores.

Deve-se destacar que as ocupações às margens das ressacas no Amapá não devem ter visibilidade apenas como problema ambiental, mas levar em consideração que a ocupação do solo urbano é produzida a partir de interesses de grupos sociais específicos, que ocupam de forma diferenciada o espaço (ALMEIDA et al., 2014). A maioria da população não está incluída em políticas públicas destinadas à ordenação e democratização do espaço das cidades, logo, ocupações irregulares são consequências da gestão urbana inadequada.

\section{Considerações Finais}

As áreas de preservação permanente são ecossistemas biodiversos e frágeis em termos de susceptibilidade a impactos antrópicos. Esses impactos têm se intensificado nas últimas décadas por falta de um planejamento urbano adequado.

Na Amazônia, a enorme quantidade de cursos d'água e áreas de várzea, somados ao modo de vida ribeirinho e a falta de suporte habitacional das capitais, tornam inevitáveis as ocupações humanas em áreas de proteção permanente.

No Município de Macapá, o estudo de caso da Lagoa dos Índios exemplifica os conflitos socioambientais que ocorrem por toda Amazônia, desrespeitando as legislações ambientais e urbanas. Verificou-se escassez de estudos que abordam a quantificação da degradação ambiental e diagnóstico da situação atual das áreas de preservação permanente na Amazônia.

\section{Referências}

ALMEIDA, K.; SILVA, V.; COSTA, J. M. Cidade, Meio Ambiente e Moradia às Margens do Rio Amazonas. In: PreALAS Patagônia - VI Foro Sur-Sur, 2014, EI Calafate. PreALAS Patagônia - IV Foro Sur-Sur, 2014. v. VI.

ANTUNES, P. Direito Ambiental como Direito Econômico - Análise Crítica. Revista de Informação Legislativa, Brasília, ano 29, n. 115, p. 321/324, jul./set. 1992. 
ARAUJO, P. Regularização Fundiária Urbana em APP: a Nova Perspectiva Trazida pela Lei Federal 11.977/2009. In: Anais do II seminário Nacional sobre Áreas de Preservação Permanente em Meio Urbano, Natal: 2012.

BARROS, V.; MORAIS FILHO, L.; LAUDARES, S.; VILLELA, L.; ÁVILA, P.; SILVA, M.; OLIVEIRA, Á.; BORGES, L. Efeitos do Novo Código Florestal sobre os Reservatórios d'Água Artificiais. In XII Congresso Nacional de Meio Ambiente de Poços De Caldas. Poços de Caldas, Minas Gerais, 2015.

BASTOS, C. Conflitos Ambientais em Áreas de Ressaca: um estudo da comunidade negra da Lagoa dos Índios em Macapá/AP. 2006. 188p. (Dissertação de Mestrado). Brasília: UnB, 2006.

BORGES, L.; REZENDE, J.; PEREIRA, J.; COELHO JÚNIOR, L.; BARROS, D. Áreas de preservação permanente na legislação ambiental brasileira. In: Ciência Rural, Santa Maria, v.41, n.7, p.1202-1210, jul, 2011. ISSN 0103-8478.

BORGES, L.; REZENDE, J. Áreas Protegidas no Interior de Propriedades Rurais: a questão das APP E RL. In: Floresta e Ambiente 2011 abr./jun.

CARVALHO, P.; FRANCISCO, J. A Função Social das Áreas de Preservação Permanente nas Cidades. In: Encontro Nacional sobre Edificações e Comunidades Sustentáveis, 2003, São Carlos. Anais do Encontro Nacional sobre Edificações e Comunidades Sustentáveis - ENECS 2003. São Carlos: Universidade Federal de São Carlos, 2003.

CUNHA, A.; SOUSA, J.; GOMES, W.; BAÍA, J.; CUNHA, H. Estudo Preliminar Sobre a Variação EspaçoTemporal de Parâmetros de Qualidade de Água no Igarapé da Fortaleza. p. 105-136. In: TAKIYAMA, L.R.; SILVA, A.Q. da (Orgs.). Diagnóstico das Ressacas do Estado do Amapá: Bacias do lgarapé da Fortaleza e Rio Curiaú, Macapá-AP, CPAq/IEPA e DGEO/SEMA, 2004. p.105-136. 2003.

GARCIA, Y. O Código Florestal Brasileiro e suas Alterações no Congresso Nacional. Artigo. Revista Geografia em Atos. Presidente Prudente, n. 12, v.1, janeiro a junho de 2012, p.54-74.

LAURINDO, V.; GAIO, D. As Áreas de Preservação Permanente do Novo Código Florestal e o Princípio da Proibição de Retrocesso Ambiental. In: 3ํㅗㄴ Seminário Nacional sobre o Tratamento de Áreas de Preservação Permanente em Meio Urbano e Restrições Ambientais ao Parcelamento do Solo, Belém, 2014.

LIMA, C. A natureza na cidade, a natureza da cidade. São Paulo, Tese (doutorado em Arquitetura e Urbanismo) - FAUUSP, 1996.

LUZ, F.; AVANCI, J.; CRUZ, B. O tratamento dispensado aos conflitos que envolvem direito ao meio ambiente e direito à moradia: Análise dos trabalhos apresentados no II Seminário Nacional sobre Áreas de Preservação Permanente no Meio Urbano. In: XV Encontro da ANPUR - ENANPUR Desenvolvimento, planejamento e governança 30 anos da ANPUR, 2013, Recife.

MACEDO, S. Paisagismo Brasileiro na Virada do Século: 1990-2010. São Paulo: Editora de São Paulo; Campinas; Editora Unicamp, 2012.

MACEDO, S.; QUEIROGA, E.; DEGREAS, H. APPs urbanas: uma oportunidade de incremento da qualidade ambiental e do sistema de espaços livres na cidade brasileira - conflitos e sucessos. In: II Seminário Nacional sobre Áreas de Preservação Permanente em Meio Urbano: abordagens, conflitos e perspectivas nas cidades brasileiras, 2012, Natal. UFRN, 2012. v. 1. p. 1-11.

MARICATO, E. Metrópole na periferia do capitalismo: ilegalidade desigualdade e violência. São Paulo: Hucitec, 1996.

MELLO, S. Na Beira do Rio tem uma Cidade: urbanidade e valorização dos corpos d'água. Tese de doutorado. Universidade de Brasília, Faculdade de Arquitetura e Urbanismo, 2008.

METZGER, J. O Código Florestal tem base científica? Artigo. Natureza \& Conservação, 8(1):1-5, 2010.

RODRIGUES, R.; FERREIRA, L.; SANTOS, M. Apontamentos para a Regularização Urbanística e Fundiária de Preservação Permanente (APP) em meio urbano na Amazônia: o caso do município de Mãe do Rio. In: 3ํ Seminário Nacional sobre o Tratamento de Áreas de Preservação Permanente em Meio Urbano e Restrições Ambientais ao Parcelamento do Solo, Belém, 2014. 
ROMERO, M. Princípios Bioclimáticos para o Desenho Urbano. ProEditores. São Paulo, 2000.

SCAGLIUSI, F.; SANTOS, R. Áreas de Preservação Permanente (Apps) no Ambiente Urbano. A Necessidade de uma Legislação Específica. In: AU. Arquitetura e Urbanismo, v. 02, p. 01-, n. 2011.

SILVA, A. A Efetividade das Medidas Alternativas na Proteção do Meio Ambiente: Aplicação da Suspensão Condicional do Processo no Caso da Orla do Lago Paranoá. Monografia. Universidade de Brasília, Faculdade de Direito, 2015.

SILVA, W.; BRAGA, C.; LIMA, V.; SILVA JÚNIOR, R.; Áreas de Preservação Permanente no Novo Código Florestal Nacional: A Questão das Matas Ciliares. Artigo. Revista Agrogeoambiental, dezembro 2009. P. 96-103.

SANTANA, M. Conflito socioambiental no uso irregular de áreas públicas na orla do Lago Paranoá. Monografia. Universidade de Brasília, Curso de Gestão Ambiental, Faculdade UnB Planaltina, 2013.

TAKIYAMA, L.; SILVA, L.; JIMENEZ, A.; PEREIRA, A.; ZACARDI, M.; FERNANDES, F.; SOUTO, F; SILVA, A.; SILVA, M.; SANTOS, C.; NETO, C.; SANTOS, C. Zoneamento Ecológico Econômico Urbano das Áreas de Ressacas de Macapá e Santana, Estado do Amapá. Relatório Técnico. Macapá, 2012.

TAKIYAMA, L.; SILVA, Q.; COSTA, P.; NASCIMENTO, S. Qualidade das águas de ressaca Bacias do Igarapé da Fortaleza e Rio Curiaú. In: TAKIYAMA, L.R.; SILVA, A.Q. da (Orgs.). Diagnóstico das Ressacas do Estado do Amapá: Bacias do Igarapé da Fortaleza e Rio Curiaú, Macapá-AP, CPAq/IEPA e DGEO/SEMA, 2004. p.105-136. 2003.

TURNER, W., BRANDON, K., BROOKS, T., COSTANZA, R., DA FONSECA, G., PORTELA, R. Global conservation of biodiversity and ecosystem services. In: Bioscience 57, 868-873, 2007.

VARGAS, M.; BASTOS. B. Conflitos ambientais urbanos e processos de urbanização na Ressaca Lagoa dos Índios em Macapá/AP. Cad. Metrop., São Paulo, v. 15, n. 29, pp. 265-288, jan/jun 2013.

VENTURA NETO, R.; CARDOSO, A. Ocupação de Margem de Rio na Metrópole Amazônica: origem local e tendências globais. In: Anais do II seminário Nacional sobre Áreas de Preservação Permanente em Meio Urbano, Natal: 2012. 